\title{
Desempenho produtivo de maracujazeiro amarelo em área com Fusarium solani
}

José Carlos Cavichioli ${ }^{1}$, Fernando Dantas da Mata ${ }^{2}$, Jeancesar de Souza Ronda ${ }^{3}$, Ana Favarini Hernandes ${ }^{4}$, Thiago Emílio Leite ${ }^{4}$, Rodrigo Aparecido Vitorino ${ }^{1}$, Leandro Fogagnoli Contiero ${ }^{5}$

${ }^{1}$ Polo Regional da Alta Paulista - APTA-Adamantina, SP. ${ }^{2}$ Syngenta, SP. ${ }^{3}$ Usina Alto Alegre, Presidente Prudente, SP.

${ }^{4}$ Engenheiro Agrônomo - Autônomo. Universidade Estadual Paulista - UNESP, SP. E-mail: jccavichioli@apta.sp.gov.br

\section{Resumo}

O uso de porta-enxertos tolerantes apresenta bons resultados no manejo da murcha de Fusarium (Fusarium solani) no maracujazeiro-amarelo (Passiflora edulis Sims), considerada um dos principais problemas na cultura, que afeta o sistema radicular da planta e não tem controle químico. 0 presente trabalho teve por objetivo avaliar a sobrevivência, o desempenho agronômico de plantas e as características físicas de frutos de maracujazeiro-amarelo (Passiflora edulis Sims) enxertadas em diferentes porta-enxertos em área com murcha de Fusarium. O experimento foi conduzido no Sítio Bela Vista, localizado no município de Pracinha, SP, no período de agosto de 2014 a maio de 2015, e adotou-se o delineamento em blocos ao acaso, com cinco tratamentos, cinco repetições e quatro plantas por parcela. Os tratamentos utilizados foram os porta-enxertos: $P$. alata Dryand, $P$. gibertii N.E. Brown, $P$. caerulea Linnaeus, enxertia dupla $P$. gibertii x $P$. edulis e plantas sem enxerto. Avaliaram-se o diâmetro do caule do porta-enxerto e do enxerto, o comprimento de ramos secundários, o número de ramos terciários, o número de plantas sobreviventes, os diâmetros longitudinal e transversal dos frutos, o número e a massa de frutos e a produtividade. O maior diâmetro do porta-enxerto foi observado em Passiflora alata enquanto que na região do enxerto foi em plantas de Passiflora edulis. O comprimento dos ramos secundários e o número de ramos terciários foram afetados pelo tipo de enxertia e pelo porta-enxerto utilizado. As maiores sobrevivências de plantas foram observadas em Passiflora alata (90\%) e Passiflora gibertii (100\%). O maior número de frutos por planta e produtividade ocorreram em plantas enxertadas sobre $P$. gibertii. A adoção da enxertia dupla utilizando-se Passiflora gibertii x Passiflora edulis e a enxertia simples com Passiflora caerulea não se mostraram eficientes no controle desta doença. As espécies Passiflora gibertii e Passiflora alata apresentaram potencial para serem utilizados como porta-enxertos para o maracujazeiro-amarelo.

Palavras-chave: enxertia; maracujá; morte prematura de plantas; patógenos de solo.

\section{Yellow passion fruit productive performance in area with fusarium}

\begin{abstract}
The use of tolerant rootstocks has shown good results in the control of Fusarium wilt in yellow passion fruit, which is considered one of the main problems in the crop as it affects the plant's root system and has no chemical control. The present study aimed to evaluate the survival rates, the agronomic performance of the plants and the physical characteristics of the yellow passion fruit (Passiflora edulis Sims) grafted on different rootstocks in area with Fusarium wilt. The experiment was carried in Pracinha, in the State of São Paulo, Brazil, from August 2014 to May 2015, and a randomized block design was adopted, with five treatments, five replications and four plants per plot. The treatments were constituted by the following rootstocks: Passiflora alata Dryand, Passiflora gibertii N.E. Brown, Passiflora caerulea Linnaeus, double grafting $P$. gibertii $\times P$. edulis and plants without grafting. The stem diameter of rootstock and the graft, the lenght of secondary branches, the number of tertiary branches, the number of surviving plants, the longitudinal and transversal diameters of the fruits, the number and mass of fruits and the productivity were evaluated. The largest diameter of the rootstock was observed in Passiflora alata while in the graft it was in plants of Passiflora edulis. The length of the secondarty branches and the number of tertiary
\end{abstract}


branches were affected by the type of grafting and the rootstock used. The highest survival rates were observed in Passiflora alata (90\%) and Passiflora gibertii (100\%). The highest number of fruits per plant and productivity occurred in plants grafted on Passiflora gibertii. The adoption of double grafting using Passiflora gibertii $x$ Passiflora edulis and simple grafting with Passiflora caerulea were not effective in the control of this disease. The species Passiflora gibertii and Passiflora alata showed the potential to be used as a rootstock for yellow passion fruit.

Keywords: graft; passion fruit; premature death of plants; soil pathogens.

\section{Introdução}

Destacando-se como o principal produtor mundial de maracujá, o Brasil produz em torno de 600 mil toneladas da fruta e uma produtividade média de 14,1 t ha ${ }^{-1}$ (IBGE, 2019), considerada baixa para a cultura, devido principalmente a ocorrência de problemas fitossanitários, como os patógenos causadores de doenças do solo, que aumentaram com a expansão desta frutífera (FISCHER; REZENDE, 2008).

A morte prematura de plantas, provocada pela associação de fungos de solo, como o Fusarium, nematoides e bactéria, como a Xanthomonas axonopodis pv. passiflorae, tem-se constituído em um dos principais problemas para a cultura no Brasil, responsável pela redução da área plantada e pelo caráter itinerante do maracujazeiro (CAVICHIOLI et al., 2011b, SILVA et al., 2017). No caso do Fusarium solani, após a penetração do patógeno nas raízes das plantas, observa-se inicialmente uma clorose nas folhas, seguido de murcha da planta, resultado da podridão do colo e do sistema radicular e, posteriormente, a morte do maracujazeiro (FISCHER; REZENDE, 2008).

Não há controle químico para essa doença, devendo utilizar-se de práticas culturais e preventivas para o seu controle, tais como: evitar áreas com histórico da doença, evitar o plantio em solos pesados e compactados, utilizar mudas sadias e evitar ferimentos no colo e nas raízes das plantas (FISCHER; RESENDE, 2008). Alguns autores tem recomendado o uso da enxertia para o controle dessa doença e algumas espécies como o $P$. gibertii, $P$. alata e $P$. foetida tem apresentado tolerância à murcha de Fusarium (NOGUEIRA FILHO et al., 2010; CAVICHIOLI et al, 2011b; SILVA et al., 2017).

Apesar da técnica da enxertia ter apresentado resultados satisfatórios no controle de Fusarium, Nogueira Filho et al. (2010) verificaram que plantas de maracujazeiro enxertadas em porta enxertos de $P$. alata, $P$. caerulea e $P$. gibertii apresentaram menor vigor e menor precocidade em relação as mudas obtidas por sementes. Cavichioli et al. (2011a) também observaram menores produtividades em plantas enxertadas sobre $P$. gibertii. Entretanto, o uso da técnica permite a convivência do maracujazeiro em áreas com Fusarium, o que não ocorre com plantas sem enxerto, justificando assim a utilização da tecnologia.

O método de enxertia mais utilizado é a hipocotiledonar por garfagem tipo fenda cheia (CAVICHIOLI et al., 2011a; SANTOS et al., 2016), entretanto Narita et al. (2012) recomendam a utilização de mudas com dois sistemas radiculares (raiz dupla), com o objetivo de aumentar o vigor de mudas enxertadas e manter o sistema radicular da planta saudável por mais tempo, utilizando o próprio $P$. edulis e o da espécie de Passiflora compatível e tolerante a doenças de solo.

O objetivo com este trabalho foi avaliar a sobrevivência, o desempenho agronômico de plantas e as características físicas de frutos de maracujazeiro-amarelo (Passiflora edulis Sims) enxertadas em diferentes porta-enxertos em área com murcha de Fusarium.

\section{Material e Métodos}

O experimento foi instalado e conduzido em uma propriedade, com murcha de Fusarium, denominada Sítio Bela Vista, município de Pracinha, estado de São Paulo, na região da Nova Alta Paulista, no período de agosto de 2014 a abril de 2015, localizado na latitude $21^{\circ} 50^{\prime} 27.45^{\prime \prime} S$ e longitude $51^{\circ} 4^{\prime} 39.13^{\prime \prime O}$. De acordo com a classificação de Santos et al. (2018), o solo da área experimental é classificado como Argissolo Vermelho Amarelo, eutrófico, A moderado, textura arenosa/média e topografia ondulada. 
O clima da região onde foi instalado o experimento é classificado como Cwa, de acordo com a classificação Koppen, com uma estação chuvosa no verão e uma estação seca no inverno, com médias de precipitação anual em torno de $1250 \mathrm{~mm}$ e temperatura média anual de $22^{\circ} \mathrm{C}$.

$\mathrm{O}$ delineamento estatístico utilizado foi em blocos ao acaso, com cinco tratamentos, cinco repetições e quatro plantas por parcela. Os tratamentos utilizados foram os porta-enxertos: Passiflora alata Dryand, Passiflora gibertii N.E. Brown, Passiflora caerulea L., enxertia por encostia (raiz dupla) $P$. gibertii $\times P$. edulis e plantas sem enxerto (Passiflora edulis Sims).

Utilizou-se o maracujazeiro-amarelo (Passiflora edulis Sims), cv. Sul Brasil, como copa. A enxertia foi realizada quando as plantas de maracujá amarelo estavam com 60 dias de germinadas e os outros materiais, com 75 dias, e os porta-enxertos e enxertos apresentavam cerca de $3 \mathrm{~mm}$ de diâmetro de caule. Foram utilizadas a enxertia por garfagem tipo fenda cheia e a enxertia por encostia (raiz dupla) para $P$. gibertii $x$ $P$. edulis. A enxertia por garfagem foi realizada a $10 \mathrm{~cm}$ de altura do caule. Para a realização da enxertia por encostia, realizou-se no cavalo $(P$. edulis), com o uso de um estilete, uma fenda oblíqua lateral de baixo para cima, sem decepar a parte aérea, enquanto nas mudas do portaenxerto foi feita uma incisão a aproximadamente $10 \mathrm{~cm}$ de altura, eliminando-se a parte aérea. $\mathrm{Na}$ sequência, abriu-se o entalhe do cavalo e inseriuse o porta-enxerto, unindo-se, assim, as partes e envolvendo-se com fita plástica. Nesse caso, o enxerto e o porta-enxerto foram mantidos com seus sistemas radiculares (raiz dupla).

As mudas foram transplantadas para o campo no dia 8 de agosto de 2014, quando estavam com 90 dias de enxertadas, adotando-se o sistema de plantio direto, em covas abertas nas dimensões de $40 \times 40 \times 40 \mathrm{~cm}$. A adubação das covas foi realizada de acordo com a recomendação de Piza Junior et al. (1996) e consistiu de $2 \mathrm{~kg}$ de esterco de galinha, $1 \mathrm{~kg}$ de calcário, $500 \mathrm{~g}$ de superfosfato simples e $50 \mathrm{~g}$ de FTE. As adubações de formação consistiram de 30 $\mathrm{g}$ de nitrato de amônio, aplicados aos 30 dias, 45 $\mathrm{g}$ de nitrato de amônio, aos 60 dias, $100 \mathrm{~g}$ da fórmula 20-05-20, aos 90 dias, e $150 \mathrm{~g}$ da fórmula 20-05-20, aos 120 dias após o plantio das mudas. A adubação de produção foi feita de acordo com os resultados da análise química de solo.

As plantas foram conduzidas em sistema de espaldeira com um fio de arame liso, adotando-se o espaçamento de 3,0 m entre plantas por 3,0 m entrelinhas. As mudas foram mantidas em haste única (ramo primário) até atingirem o fio de arame da espaldeira, sendo eliminadas todas as brotações laterais. Ao atingir o fio de arame, o ramo principal foi podado no ápice, deixando crescer um ramo para cada lado da espaldeira (ramos secundários). Os ramos que saíram destes ramos secundários não foram desbrotados, crescendo livremente, chamados de ramos terciários.

Foram avaliadas as seguintes características: os diâmetros do caule do portaenxerto e do enxerto, medidos a $1 \mathrm{~cm}$ e $12 \mathrm{~cm}$ do colo, respectivamente, com o auxílio de um paquímetro de precisão de $0,1 \mathrm{~mm}$, aos 180 dias após o plantio; o comprimento dos ramos secundários, realizado com uma régua graduada em $\mathrm{mm}$, medindo-se da inserção com o ramo principal até o ponteiro, aos 120 dias do plantio e o número de ramos terciários, contados aos 120 dias após o plantio; a sobrevivência de plantas, calculada pela contagem de plantas vivas no final do experimento; o diâmetro longitudinal e o diâmetro transversal de frutos, realizados mensalmente no período de dezembro de 2014 a abril de 2015, coletando-se uma amostra de 10 frutos por parcela e medindo-os com auxílio de um paquímetro de precisão $0,1 \mathrm{~mm}$; o número de frutos por planta, obtido pela contagem dos mesmos após cada colheita, realizada três vezes por semana, no período de agosto de 2014 a abril de 2015; a massa média de frutos, obtida pela massa total de frutos sadios de cada colheita dividido pelo número de frutos e a produtividade, obtida após cada colheita, pesando-se os frutos em balança de precisão de $1 \mathrm{~g}$, calculando-se a produtividade em $\mathrm{kg} \mathrm{ha}^{-1}$.

Os dados foram submetidos à análise de variância com a realização do teste $\mathrm{F}$, e as médias, comparadas pelo teste de Tukey, a $5 \%$ de probabilidade. Os dados de número de frutos foram transformados em log $(x+1)$. Os cálculos referentes às análises estatísticas foram executados utilizando-se do software Assistat 7.7 (SILVA; AZEVEDO, 2016).

\section{Resultados e Discussão}

Os maiores diâmetros do caule do porta-enxerto, aos 180 dias de idade, foram observados no $P$. alata, que diferiram significativamente dos demais tratamentos (Tabela 1), concordando com os resultados de Cavichioli et al. (2011a). Os menores 
diâmetros foram observados nas plantas com enxertia dupla $P$. gibertii $\times P$. edulis, enquanto os tratamentos $P$. gibertii e $P$. caerulea não diferiram entre si (Tabela 1). De acordo com
Morgado et al. (2015), o uso de portaenxertos mais vigorosos proporciona altas produtividades e melhor qualidade de frutos.

Tabela 1. Diâmetro do caule do porta-enxerto (DPE), diâmetro do caule do enxerto (DE), medido aos 180 dias, comprimento dos ramos secundários (CR) e número de ramos terciários (NR), aos 120 dias e sobrevivência de plantas (SOBR) aos 180 dias do plantio no campo. Pracinha, SP, 2015.

\begin{tabular}{lccccc}
\hline Tratamentos & $\begin{array}{c}\mathrm{DPE} \\
(\mathrm{mm})\end{array}$ & $\begin{array}{c}\mathrm{DE} \\
(\mathrm{mm})\end{array}$ & $\begin{array}{c}\mathrm{CR} \\
(\mathrm{cm})\end{array}$ & NR & $\begin{array}{c}\text { SOBR } \\
(\%)\end{array}$ \\
\hline P. alata & $32,35 \mathrm{a}$ & $23,42 \mathrm{~b}$ & $129,70 \mathrm{~b}$ & $8,45 \mathrm{bc}$ & $90,00 \mathrm{a}$ \\
P. gibertii & $21,28 \mathrm{c}$ & $21,33 \mathrm{c}$ & $161,78 \mathrm{ab}$ & $11,45 \mathrm{ab}$ & $100,00 \mathrm{a}$ \\
P. caerulea & $23,77 \mathrm{c}$ & $18,57 \mathrm{~d}$ & $128,65 \mathrm{~b}$ & $5,26 \mathrm{c}$ & $15,00 \mathrm{~b}$ \\
P. gibertii $x$ P. edulis & $11,55 \mathrm{~d}$ & $21,33 \mathrm{c}$ & $179,55 \mathrm{a}$ & $13,95 \mathrm{a}$ & $20,00 \mathrm{~b}$ \\
P. edulis (não enxertado) & $27,95 \mathrm{~b}$ & $25,50 \mathrm{a}$ & $177,04 \mathrm{a}$ & $11,85 \mathrm{a}$ & $0,00 \mathrm{~b}$ \\
\hline F & $75,74^{* *}$ & $42,87^{* *}$ & $10,00 * *$ & $20,96 * *$ & $26,46^{* *}$ \\
CV (\%) & 8,60 & 4,02 & 11,30 & 16,20 & 44,79 \\
\hline
\end{tabular}

Médias seguidas da mesma letra, na coluna, não diferem entre si pelo Teste de Tukey, à $5 \%$

** Significativo ao nível de $1 \%$ pelo Teste de Tukey

$\mathrm{Na}$ avaliação de diâmetro na região do enxerto não se verificou o mesmo comportamento que o verificado na região do porta-enxerto, uma vez que os maiores diâmetros ocorreram em plantas não enxertadas, diferindo dos demais tratamentos (Tabela 1), o que concorda com Cavichioli et al. (2011a). Esse resultado indica que plantas não enxertadas são mais vigorosas que plantas enxertadas, independente do porta-enxerto.

Observou-se o menor comprimento de ramos secundários em plantas enxertadas sobre $P$. caerulea que diferiu das plantas com enxertia dupla e de plantas não enxertadas (Tabela 1). Cavichioli et al. (2011a) também verificaram o maior comprimento de ramos em plantas não enxertadas. O mesmo verificou-se para o número de ramos terciários, onde o maior número de ramos em plantas ocorreu na enxertia dupla $P$. gibertii $\times P$. edulis e em plantas não enxertadas, que também não diferiram de plantas $P$. gibertii (Tabela 1). Esses resultados evidenciam que 0 comprimento dos ramos secundários e o número de ramos terciários são afetados pelo tipo de enxertia e pelo porta-enxerto utilizado.

Os maiores índices de sobrevivência de plantas do maracujazeiro-amarelo foram observados em plantas enxertadas em $P$. gibertii com $100 \%$ de plantas sobreviventes que não diferiram das plantas enxertadas em $P$. alata, com $90 \%$ de plantas sobreviventes (Tabela 1 ). Cavichioli et al. (2011b) verificaram a sobrevivência de $91,4 \%$ em $P$. gibertii e 60,0\% em
P. alata em área com histórico de morte prematura de plantas. Plantas com $P$. caerulea e com enxertia dupla $P$. gibertii $\times \quad P$. edulis apresentaram 15 e $20 \%$ de sobrevivência enquanto que não houve plantas sobreviventes para o tratamento com plantas sem enxerto.

Não houve diferenças para o diâmetro longitudinal de frutos que variou de $10,69 \mathrm{~cm}$ nas plantas enxertadas em $P$. caerulea a $11,42 \mathrm{~cm}$ nas plantas sem enxerto (Tabela 2), concordando com Hurtado-Salazar et al. (2015) que também não verificaram diferenças entre plantas não enxertadas e enxertadas em $P$. gibertii, obtendo $8,33 \mathrm{~cm}$ e $8,18 \mathrm{~cm}$ de diâmetro, respectivamente e também com os resultados obtidos por Cavichioli et al. (2011a) que variou de $9,92 \mathrm{~cm}$ no tratamento com $P$. gibertii a $10,91 \mathrm{~cm}$ em plantas sem enxerto. Os resultados verificados para esta variável foram próximos aos obtidos por Botelho et al. (2017) que, estudando a variedade BRS Gigante Amarelo no município de Cáceres, MT, obtiveram $10,21 \mathrm{~cm}$ de diâmetro longitudinal.

Frutos de plantas enxertadas em $P$. caerulea apresentaram menor diâmetro transversal comparado aos frutos de plantas de $P$. edulis sem enxerto que não diferiram de $P$. gibertii. Hurtado-Salazar et al. (2015) diferentemente dos resultados aqui obtidos, verificaram que que o diâmetro transversal de frutos de plantas não enxertadas foi superior ao diâmetro de plantas enxertadas em $P$. gibertii. Em plantas enxertadas, foi observado o diâmetro transversal de $9,11 \mathrm{~cm}$, próximos aos obtidos por 
Botelho et al. (2017) em Cáceres, MT, com 9,05 $\mathrm{mm}$ e por Pereira et al. (2018), no Sudoeste de Goiás, com 9,19 mm. Essa é uma importante característica, pois os frutos de maracujá são classificados pelo seu diâmetro equatorial para fins de comercialização, ou seja, quanto maior o diâmetro, melhor a classificação e o preço pago ao produto. Assim, de acordo com as normas do programa brasileiro para melhoria dos padrões
Comerciais e Embalagens de Hortigranjeiros, os frutos de maracujazeiro sem enxerto atingiram a classe 5 (> 8,5 mm), enquanto que os frutos de plantas enxertadas sobre $P$. alata, $P$. gibertii e enxertia dupla $P$. gibertii $\times P$. edulis atingiram a classe $4(7,5$ a $8,5 \mathrm{~mm})$ e os frutos de plantas enxertadas sobre $P$. caerulea, a classe $3(6,5$ a 7,5 $\mathrm{mm})$.

Tabela 2. Diâmetro longitudinal de frutos (DLF), diâmetro transversal de frutos (DTF), número de frutos por planta (NF), massa média de frutos (MF) e produtividade de maracujazeiro-amarelo pé-franco e enxertado. Pracinha, SP, 2015.

\begin{tabular}{lccccc}
\hline Tratamentos & $\begin{array}{l}\text { DLF } \\
(\mathrm{cm})\end{array}$ & $\begin{array}{c}\text { DTF } \\
(\mathrm{cm})\end{array}$ & NF & $\begin{array}{c}\text { MF } \\
(\mathrm{g})\end{array}$ & $\begin{array}{c}\text { PROD } \\
\left(\mathrm{t} \mathrm{ha}^{-1}\right)\end{array}$ \\
\hline P. alata & $10,74 \mathrm{a}$ & $7,57 \mathrm{ab}$ & $26,6 \mathrm{ab}$ & $175 \mathrm{~b}$ & $5,04 \mathrm{~b}$ \\
P. gibertii & $10,73 \mathrm{a}$ & $8,08 \mathrm{ab}$ & $69,6 \mathrm{a}$ & $212 \mathrm{ab}$ & $15,11 \mathrm{a}$ \\
P. caerulea & $10,69 \mathrm{a}$ & $7,39 \mathrm{~b}$ & $10,0 \mathrm{~b}$ & $185 \mathrm{~b}$ & $1,84 \mathrm{~b}$ \\
P. gibertii $x$ P. edulis & $10,83 \mathrm{a}$ & $7,85 \mathrm{ab}$ & $15,2 \mathrm{~b}$ & $159 \mathrm{~b}$ & $2,84 \mathrm{~b}$ \\
P. edulis (não enxertado) & $11,42 \mathrm{a}$ & $9,11 \mathrm{a}$ & $7,8 \mathrm{~b}$ & $264 \mathrm{a}$ & $2,05 \mathrm{~b}$ \\
\hline F & $1,27 \mathrm{~ns}$ & $3,24 *$ & $21,6 * *$ & $7,80 * *$ & $22,96^{* *}$ \\
CV (\%) & 5,52 & 10,48 & 25,3 & 16,58 & 48,42 \\
\hline
\end{tabular}

Médias seguidas da mesma letra, na coluna, não diferem entre si pelo Teste de Tukey, à $5 \%$ ns - não significativo. * significativo ao nível de $5 \%$, ${ }^{* *}$ significativo ao nível de $5 \%$.

Plantas enxertadas em $P$. gibertii tiveram o maior número de frutos, com 69,6 frutos por planta, não diferindo de $P$. alata, com 29,6 frutos por planta, mas superior aos demais tratamentos (Tabela 2), concordando com os resultados de Cavichioli et al. (2011b) que, trabalhando em área com histórico de morte prematura também observaram o maior número de frutos em plantas enxertadas em $P$. gibertii, com 14,24 frutos por planta. O resultado diferiu de Nogueira Filho et al. (2010) que observaram o maior número de frutos em plantas não enxertadas, mas sem diferir de $P$. gibertii. Devese salientar que estes resultados foram obtidos em área sem histórico de patógenos de solo. Aguiar et al. (2017), avaliando os efeitos de diferentes doses de biofertilizantes no município de Nova Floresta, no estado da Paraíba, obtiveram a média de 34,15 frutos por planta, com a variedade Gigante amarelo, resultado inferior aos obtidos neste trabalho quando enxertado em $P$. gibertii. As diferenças observadas para o número de frutos podem ser explicadas pelo alto índice de mortes de plantas observados nos tratamentos sem enxertia e nos enxertados em $P$. caerulea e $P$. gibertii $\times P$. edulis.

A maior massa de frutos, foi observada em plantas de $P$. edulis não enxertadas, com 264 g, que não diferiu de plantas enxertadas em $P$. gibertii, com $212 \mathrm{~g}$, mas superior aos tratamentos enxertados com $P$. alata, $P$. caerulea e $P$. edulis $\mathrm{x}$ $P$. gibertii (Tabela 2). Esses resultados diferiram dos obtidos por Nogueira Filho et al. (2010) que não verificaram diferenças entre as massas de frutos obtidos de plantas não enxertadas (148 g) e enxertadas em P. gibertii (155 g) e $P$. caerulea (150 g). O valor da massa de frutos obtidos neste estudo também foi superior aos resultados encontrados por Silva et al. (2016), com 207,9 g, em frutos produzidos no Vale do São Francisco, no estado da Bahia, mas inferior aos de Pereira et al. (2018), trabalhando com a variedade FB 200 no Sudoeste de Goiás, que obtiveram valores médios para massa de frutas de $310 \mathrm{~g}$, superiores aos obtidos neste trabalho. As diferenças encontradas para a massa de frutos devem-se aos diferentes locais onde foram realizados os trabalhos e aos materiais genéticos utilizados.

Verificou-se a maior produtividade em plantas enxertadas em $P$. gibertii, diferindo dos demais tratamentos (Tabela 2). Esse resultado concorda com Cavichioli et al. (2011b) que observaram maior produtividade do $P$. gibertii quando comparado com $P$. edulis e $P$. alata em área com histórico de morte prematura de plantas. Figueiredo et al. (2015) trabalhando com 
maracujazeiro amarelo com diferentes formas de condução das plantas no Semiárido Brasileiro obtiveram valores que variaram de 2,94 a 7,65 t ha $^{-1}$, próximos aos obtidos neste trabalho, com exceção para as plantas enxertadas em $P$. gibertii. Os valores observados no presente estudo ficaram abaixo da produtividade média brasileira, que é de 14,1 tha ${ }^{-1}$ (IBGE, 2019), com exceção das plantas enxertadas sobre $P$. gibertii, que foi de $15,11 \mathrm{t} \mathrm{ha}^{-1}$. Esses resultados podem ser explicados em razão do alto índice de mortes verificados nas plantas não enxertadas e nas enxertadas em $P$. caerulea e em $P$. gibertii $\times P$. edulis.

\section{Conclusões}

Plantas de maracujazeiro amarelo enxertadas sobre Passiflora gibertii apresentaram as maiores produtividades e $100 \%$ de sobrevivência em área com Fusarium solani.

As espécies Passiflora edulis e Passiflora caerulea mostraram-se suscetíveis ao Fusarium, não sendo recomendadas para áreas com histórico da doença.

\section{Agradecimentos}

Ao produtor Laércio Biasi pela cessão da área para condução do experimento

\section{Referências}

AGUIAR, A. V. M. de; CAVALCANTE, L. F.; SILVA, R. M. da; DANTAS, T. A. G.; SANTOS, E. C. dos. Effect of biofertilization on yellow passion fruit production and fruit quality. Revista Caatinga, Mossoró, v. 30, n.1, p. 136-148, 2017. https://doi.org/10.1590/1983-

\section{7v30n115rc}

BOTELHO, S. C. C.; RONCATTO, G.; BOTELHO, F. M.; OLIVEIRA, S. S.; WOBETO, C. Qualidade póscolheita de frutos de maracujazeiro-amarelo produzidos em Mato Grosso. Nativa, Sinop, v. 5, edição especial, p. 471-476, 2017.

https://doi.org/10.5935/2318-7670.v05nespa02

CAVICHIOLI, J. C.; CORRÊA, L. de S.; BOLIANI, A. C.; SANTOS, P. C. Desenvolvimento e produtividade de maracujazeiro-amarelo enxertado em três porta-enxertos. Revista Brasileira de Fruticultura, Jaboticabal, v. 33, n. 2, p. 558-566, 2011a. https://doi.org/10.5935/23187670.v05nespa02
CAVICHIOLI, J. C.; CORRÊA, L. de S.; BOLIANI, A. C.; GARCIA, M. J. M.; FISCHER, I. H. Desenvolvimento, produtividade e sobrevivência de maracujazeiro-amarelo enxertado e cultivado em área com histórico de morte prematura de plantas. Revista Brasileira de Fruticultura, Jaboticabal, v. 33, n. 2, p. 567-574, 2011b.

https://doi.org/10.1590/S0100-

29452011005000075

INSTITUTO BRASILEIRO DE GEOGRAFIA E ESTATÍSTICA (IBGE). Produção agrícola municipal. Brasília, DF: IBGE, 2019. Disponível em: https://sidra.ibge.gov.br/tabela/1613. Acesso em: 9 mar. 2020.

FIGUEIREDO, F. R. A.; HAFLE, O. M.; RODRIGUES, M. H. B. S.; PEREIRA JÚNIOR, E. B.; DELFINO, F. I. Produtividade e qualidade dos frutos do maracujazeiro-amarelo sob diferentes formas de condução das plantas. Agropecuária Científica no Semiárido, Campina Grande, v. 11, n. 4, p. 23-32, 2015.

FISCHER, I. H.; RESENDE, J. A. M. Diseases of passion flower (Passiflora spp.). Pest Technology, Kagawa, v. 2, n. 1, p. 1-19, 2008.

HURTADO-SALAZAR, A.; SILVA, D. F. P. da; SEDIYAMA, C. S.; BRUCKNER, C. H. Caracterização física e química de frutos de maracujazeiroamarelo enxertado em espécies silvestres do gênero passiflora cultivado em ambiente protegido. Revista Brasileira de Fruticultura, v. 37, n. 3, p. 635-643, 2015.

https://doi.org/10.1590/0100-2945-101/14

MORGADO, M. A. D.; BRUCKNER, C. H.; ROSADO, L. D. S.; SANTOS, C. E. M. Desenvolvimento de mudas de maracujazeiro-azedo enxertadas em espécies silvestres de Passiflora. Revista Brasileira de Fruticultura, Jaboticabal, v. 37, n. 2, p. 471-479, 2015. https://doi.org/10.1590/01002945-099/14

NARITA, N.; RÓS, A. B.; CAVICHIOLI, J. C.; SUGUINO, E.; LUCAS, C. dos S.; HIRATA, A. C. S. Crescimento inicial de plantas de maracujazeiroazedo com raiz dupla em função da espécie enxertada lateralmente. In: CONGRESSO BRASILEIRO DE FRUTICULTURA, 22., 2012, Bento Gonçalves. Anais [...]. Bento Gonçalves, RS: SBF, 2012. p. 5340-5343. 
NOGUEIRA FILHO, G. C.; RONCATTO, G.; Carlos RUGGIERO, C.; OLIVEIRA, J.C. de; MALHEIROS, E.B. Desenvolvimento e produção das plantas de maracujazeiro-amarelo produzidas por enxertia hipocotiledonar sobre seis portaenxertos. Revista Brasileira de Fruticultura, Jaboticabal, v. 32, n. 2, p. 535-543, 2010.

https://doi.org/10.1590/S0100$\underline{29452010005000071}$

PEREIRA, L. D.; VALLE, K. D. do; SOUZA, L. K. F. de; ASSUNÇÃO, H. F.; BOLINA, C. de C.; REIS, E. F. dos; SALAZAR, A. H.; SILVA, D. F. P. da. Caracterização de frutos de diferentes espécies de maracujazeiro. Revista Brasileira de Agropecuária Sustentável, v. 8, n. 2, p. 21-28, 2018. https://doi.org/10.21206/rbas.v8i2.502

PIZA JUNIOR, C. de T.; QUAGGIO, J. A.; MELETTI, L. M. M.; SILVA, J. R da; SÃO JOSÉ, A. R.; KAVATI, R. Maracujá. In: RAIJ, B. V.; CANTARELLA, H.; QUAGGIO, J. A.; FURLANI, A. M. C. Recomendações de adubação e calagem para o Estado de São Paulo. 2. ed. Campinas: Instituto Agronômico, 1996. 285 p. (Boletim Técnico, 100).

SANTOS, C. H. B., CRUZ NETO, A. J. da; SOARES, T. L.; OLIVEIRA, E. J. de; JESUS, O. N. de; GIRARDI, E. A. Porta-enxertos e fixadores de enxerto para enxertia hipocotiledonar de maracujazeiro azedo. Ciência Rural, Santa Maria, v. 46, n. 1, p. 30-35, 2016. https://doi.org/10.1590/0103-

$\underline{8478 \mathrm{cr} 20140154}$

SANTOS, H. G. dos JACOMINE, P. K. T., ANJOS, L. H. C. dos et al. Sistema brasileiro de classificação de solos. 5. ed. Brasília, DF: Embrapa, 2018. 356 p.

SILVA, F. A. S.; AZEVEDO, C. A. V. The Assistat Software Version 7.7 and its use in the analysis of experimental data. African Journal Agricultural Research, v. 11, n. 39, p. 3733-3740, 2016.

https://doi.org/10.5897/AJAR2016.11522

SILVA, M. S.; ATAÍDE, E. M.; SANTOS, A. K. E.; SOUZA, J. M. A. Qualidade de frutos de maracujazeiro amarelo produzidos na safra e entressafra no Vale do São Francisco. Revista Iberoamericana de Tecnología Postcosecha, Hermosillo, v. 17, n. 1, p. 41-49, 2016.

http://www.redalyc.org/articulo.oa?id=81346341 $\underline{006}$
SILVA, R. M.; AMBRÓSIO, M. M. Q.; AGUIAR, A. V. M.; FALEIRO, F. G.; CARDOSO, A. M. S.; MENDONÇA, V. Reação de cultivares de maracujazeiro em áreas com fusariose. Summa Phytopathologica, Botucatu, v. 43, n. 2, p. 98102, 2017. https://doi.org/10.1590/0100- 